\title{
Expression of Bax and Apoptosis-Related Proteins in Human Esophageal Squamous Cell Carcinoma Including Dysplasia
}

Atsushi Kurabayashi, Mutsuo Furihata, Manabu Matsumoto, Yuji Ohtsuki, Shiro Sasaguri, Shohei Ogoshi

Departments of Pathology II (AK, MF, MM, YO) and Surgery II (AK, SS), and Vice President (SO), Kochi

Medical School, Nankoku, Kochi, Japan

The rate of tumor growth depends on the balance between proliferation and death of tumor cells. It is known that Bax, caspase-3, and p53 proteins are death-promoting factors, whereas Bcl-2 protein is a death antagonist. We immunohistochemically examined the expression of Bax and apoptosis-related proteins such as caspase-3, p53, and Bcl-2 in 76 patients with human esophageal squamous cell carcinoma (SCC) including dysplasia to determine the relationship of expression of each protein to tumor behavior and patients' prognosis. No significant relationships in immunopositivity were found among these proteins in SCCs. Cytoplasmic Bax expression was exhibited in 63 cases of SCCs (82.9\%). The apoptotic index of caspase-3-positive lesions was significantly higher than that of caspase-3-negative lesions in both dysplasia and SCC $(P=.016, P=.012)$. On the other hand, the apoptotic index $(1.18 \%)$ was significantly correlated with Bax overexpression in dysplasia $(P=.006)$, but not in SCC lesions $(P=$ .129). The patients with Bax-positive SCCs were found to have a poor prognosis by the Kaplan-Meier method $(P=.043)$. These findings suggested that Bax expressed in dysplasia may play a role as an apoptotic factor, but that it may be functionally inactive in some cancerous lesions and thus not contribute to suppression of the tumor progression in some cases of human esophageal SCCs.

KEY WORDS: 58 Bax, Esophageal squamous cell carcinoma, Immunohistochemistry, TUNEL method.

Mod Pathol 2001;14(8):741-747

Copyright $\odot 2001$ by The United States and Canadian Academy of Pathology, Inc.

VOL. 14, NO. 8, P. 741, 2001 Printed in the U.S.A.

Date of acceptance: March 23, 2001.

Address reprint requests to: Mutsuo Furihata M.D., Department of Pathology II, Kochi Medical School, Nankoku, Kochi, 783-8505, Japan; fax: 81-088-880-2336.
The apoptosis pathway is regulated by several factors such as p53 and members of the Bcl-2 protein family $(1,2)$. Wild-type p53 protein physiologically acts as a DNA-binding transcription factor and may drive apoptosis as a result of DNA-damaging events (1). Members of the Bcl-2 protein family such as $\mathrm{Bax}, \mathrm{Bak}, \mathrm{Bcl}-2$, and $\mathrm{Bcl}-\mathrm{X}_{\mathrm{L}}$ influence apoptosis or cell cycle entry $(3,4)$. When Bax is present in excess, Bax/Bax homodimers are formed, which promote apoptosis $(5,6)$. Bax protein is present predominantly in the cytosol, and is able to release cytochrome $\mathrm{c}$ from mitochondria by changes in mitochondrial membrane permeability or electric potential (7-10). Release of cytochrome c leads to activation of caspase-9, which then activates caspase-3 (11). Caspases are able to activate DNase and are thus required for the typical DNA fragmentation found in apoptosis $(12,13)$.

Previous studies reported that cytoplasmic immunostaining of Bax protein was found uniformly in all cell layers of the normal squamous epithelium, and that in contrast, gradual loss of immunoreactivity for Bax was found in a fraction of preneoplastic and neoplastic lesions $(14,15)$. Sarbia et al. then also examined Bax expression in severe dysplasia in esophageal epithelium and squamous cell carcinoma (SCC) including carcinoma in situ, invasive carcinomas and lymph node metastasis, but found no significant difference in immunoreactivities among these lesions (14). Bax immunostaining has been reported to be inversely correlated with p53 immunostaining in oral and oropharyngeal carcinoma (16). On the other hand, no association between Bax and p53 immunostaining in breast and colon adenocarcinoma, and liver metastasis of colorectal carcinoma was reported by other investigators (1719). Then, Krajewski et al. reported that loss of Bax immunostaining was strongly associated with tumor progression and with shorter survival of patients with metastatic breast adenocarcinoma (20). In contrast, no association between expres- 
sion of Bax and increase of apoptosis was reported by another group $(16,21)$. Thus, the nature of the correlation between apoptosis and Bax expression in vivo has remained controversial.

In the present study, we extended these findings for Bax to in vivo conditions in human esophageal SCC including dysplasia, to elucidate the roles of expression of Bax and apoptosisrelated factors such as caspase-3, Bcl-2, and p53 in tumor development and to assess their prognostic value. Because Bax and caspase- 3 proteins act to promote cell death, we estimated the apoptotic index (AI) by the TUNEL method for SCCs for comparison with expression of Bax and caspase-3 proteins.

\section{MATERIALS AND METHODS}

\section{Patients and Tumor Samples}

Seventy-six cases of primary human esophageal SCCs consecutively obtained at esophagectomy in the Department of Surgery II, Kochi Medical School, between 1982 and 1999 were studied. All patients had received mild chemotherapy with bleomycin $\left(20 \mathrm{mg} / \mathrm{m}^{2}\right)$ daily orally administered over 5 days, but no radiation therapy before surgery. Of the patients, $66(86.8 \%)$ were male and 10 $(13.2 \%)$ were female. The mean age was 64.0 years (range 41 to 76 years). In all cases, histologic or clinical classification was performed using the Guidelines for Clinical and Pathological Studies on Carcinoma of the Esophagus established by the Japanese Society for Esophageal Disease (1999). Tumor specimens were fixed in $10 \%$ buffered formalin, processed routinely and embedded in paraffin. In each case, all available hematoxylin and eosin-stained sections were reviewed, and a representative block was chosen for further studies.

Immunohistochemistry with Bax, Caspase-3, Bcl2, and p53 Antibodies

Five micrometer-thick sections from archival formalin-fixed paraffin-embedded tissues were placed on poly-L-lysine-coated slides (Sigma Chemical Co., St. Louis, MO) for immunohistochemistry. Bax, caspase-3, Bcl-2, and p53 protein expressions were assessed by immunohistochemical examination with antibodies as detailed in Table 1. For each antibody, the deparaffinized tissue sections were placed in $10 \mathrm{~mm}$ citrate buffer, $\mathrm{PH}$ 6.0, and heated to $132^{\circ} \mathrm{C}$ in an autoclave for $12 \mathrm{~min}$. After incubation with each antibody at $4^{\circ} \mathrm{C}$ overnight, immunohistochemical staining for these proteins was performed by the avidin-biotin complex procedure with a strepta-
TABLE 1. Panel of Antibodies Used for Immunohistochemistry on Dewaxed Paraffin Sections

\begin{tabular}{clcl}
\hline Specificity & \multicolumn{1}{c}{ Clone } & Dilution & \multicolumn{1}{c}{ Source } \\
\hline $\begin{array}{c}\text { Polyclonal } \\
\text { Caspase-3 }\end{array}$ & NCL-CPP32p & $1 / 50$ & Novocastra, UK \\
$\begin{array}{c}\text { Monoclonal } \\
\text { Bax }\end{array}$ & B-9 & $1 / 40$ & Santa Cruz, UK \\
Bcl-2 & Clone 124 & $1 / 5$ & DAKO, Denmark \\
p53 & DO-7 & $1 / 30$ & DAKO, Denmark \\
\hline
\end{tabular}

vidin biotin complex peroxidase kit (Histofine LSAB Kit; DAKO, Kyoto, Japan). The specificity of the antibodies used was checked with positive or negative control sections of various kinds of tissues. In agreement with previous studies $(15,22)$, immunostaining with each antibody was considered positive if the chromogen was detected in more than $5 \%$ of all cancer cells examined. In cases of positive staining with anti-human Bax, Bcl-2, and caspase- 3 antibodies, each score was ranked as $1+, 5$ to $75 \%$ positive, or $2+$, more than $75 \%$ positive.

\section{TUNEL Method}

Apoptotic cells and bodies were visualized using the ApopTag Plus Peroxidase In Situ Apoptosis Detection Kit (Intergen Company, New York) as described in the kit manual. Briefly, after routine deparaffinization, sections were incubated with proteinase $\mathrm{K}(20 \mu \mathrm{g} / \mathrm{mL})$ (Wako, Osaka, Japan) in Tris-HCl buffer ( $\mathrm{pH}$ 7.4) for $15 \mathrm{~min}$ at room temperature. The sections were subjected to enzymic homopolymeric tailing with TdT and digoxigenin-labeled nucleotides for 60 min at $37^{\circ} \mathrm{C}$ in a humidified atmosphere. The nucleotides incorporated were revealed by incubation with anti-digoxigenine antibody conjugated to peroxidase for $30 \mathrm{~min}$ at room temperature. The peroxidase label was then visualized by the diaminobenzine (Sigma Chemical Co.) reaction. In positive controls, sections were treated with DNase I $(0.7 \mu \mathrm{g} / \mathrm{mL}$ Stratagene Co., La Jolla, CA) for 15 min before treatment with TdT. In negative controls, TdT was replaced by Tris buffer. In agreement with previous studies $(16,23,24)$, the apoptotic cells were counted in areas with high frequency under 10 high-power fields. More than 1000 tumor cells were counted to calculate the AI from these areas, and the AI values were expressed as percentages of TUNEL-positive cells. Apoptotic cells were not evaluated from the vicinity of necrotic areas.

\section{Statistical Analysis}

Statistical associations between Bax and caspase-3, Bax and p53, Bcl-2 and p53, and between each Bax, caspase-3, p53, or Bcl-2 protein expression and various clinicopathologic factors were determined using the $x^{2}$ test $(P<.05)$. The cumulative survival rates were calculated by the 
TABLE 2. The Details of Expression Patterns Regarding the Percentage of Positive Cells for Bax, Caspase-3, Bcl2, and p53 Antibodies

\begin{tabular}{lccc}
\hline \multirow{2}{*}{ Antibodies } & \multicolumn{3}{c}{ Number of cases (\%) } \\
\cline { 2 - 4 } & $2+$ & $1+$ & Negative \\
\hline Bax & $32(42.1 \%)$ & $31(40.8 \%)$ & $13(17.1 \%)$ \\
Caspase-3 & $10(13.5 \%)$ & $31(41.9 \%)$ & $33(44.6 \%)$ \\
Bcl-2 & $5(6.6 \%)$ & $14(18.4 \%)$ & $57(75.0 \%)$ \\
p53 & $17(22.4 \%)$ & $28(36.8 \%)$ & $31(40.8 \%)$ \\
\hline
\end{tabular}

Kaplan-Meier method, and the statistical significance of differences was determined using the log-rank test $(P<.05)$. The significance of relationships between $\mathrm{AI}$ and expression of Bax or caspase-3 was determined by Mann-Whitney test $(P<.05)$.

\section{RESULTS}

Immunohistochemistry with Bax, Caspase-3, Bcl2, and p53 Antibodies

In total, 63 of 76 (82.9\%), 41 of 74 (55.4\%), 19 of 76 (25.0\%), and 45 of 76 (59.2\%) SCCs exhibited $1+$ or $2+$ positive staining with Bax, caspase-3, Bcl-2, and p53antibodies, respectively. Percentages of cells positive
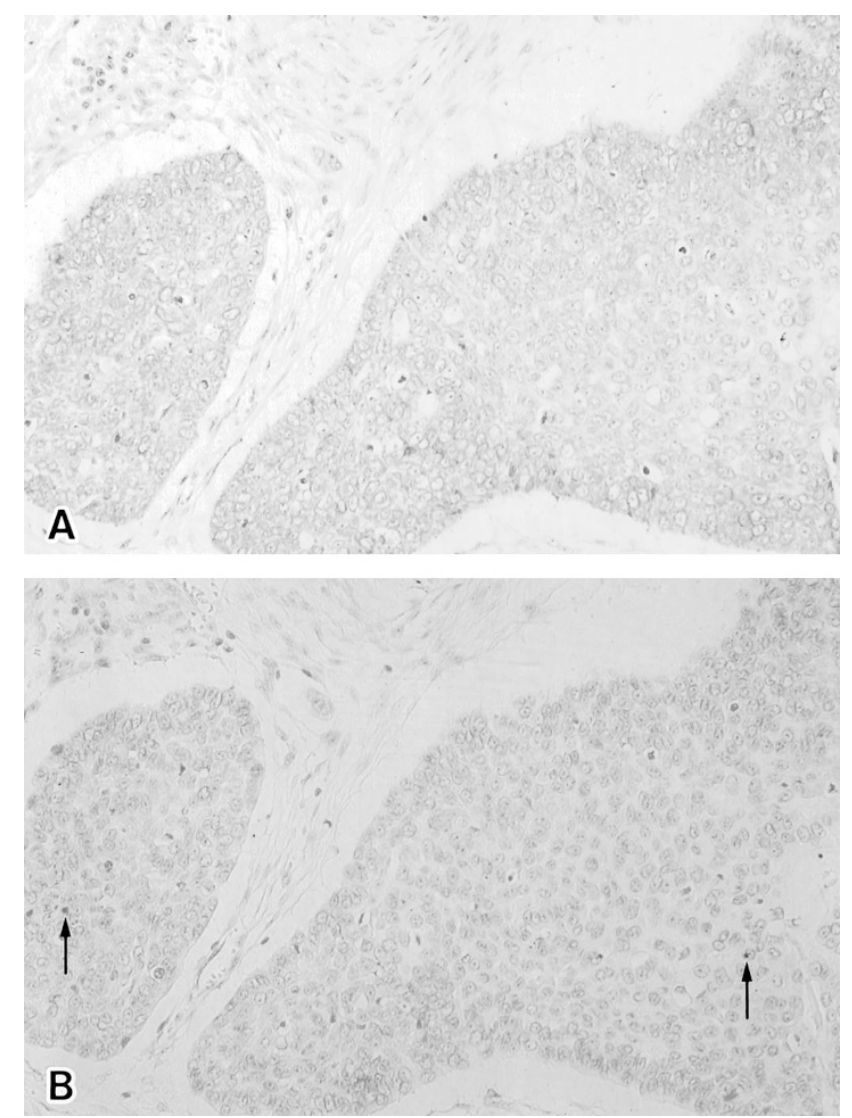

FIGURE 1. Homogenous Bax-immunopositivity (A), but no apoptotic cells were detected in an identical area of a case of esophageal SCC (B). Only a small number of TUNEL-positive lymphocytes (arrows) were observed. (A) LSAB method; X 200, (B) TUNEL method; X 200 for each antibody are summarized in Table 2. Bax, caspase-3, and Bcl-2 immunoreactivities were mainly observed in the cytoplasm of cancer cells. p53 positivity was restricted to the nucleus of cancer cells. In the normal esophageal epithelium, Bax and caspase-3 immunoreactivity were found in all layers, whereas Bcl-2 immunoreactivity was found mainly in the basal layer. None of the non-neoplastic cells showed evidence of p53 staining as detected by immunohistochemistry. There was no significant difference in both frequency and intensity of immunoreactivities of these proteins in both noninvasive and invasive parts, and there were no significant relationships in immunoreactivity among Bax, caspase-3, p53, and Bcl-2 in esophageal SCCs.

\section{TUNEL Method}

The mean AI for all esophageal SCCs examined was $2.40 \%$ (range 0.00 to $9.80 \%$ ) and median $\mathrm{AI}$ was $2.00 \%$. The mean AI was $2.57 \%$ (range 0.00 to $9.80 \%$ ) in cases with Bax immunoreactivity, and $1.55 \%$ (range 0.00 to $3.10 \%$ ) in cases without it. There was no significant relationship between Bax immunoreactivity and $\mathrm{AI}$ in esophageal SCCs $(P=.129)$. In some cases, homogenous Bax-immunopositivity but no apoptotic cells
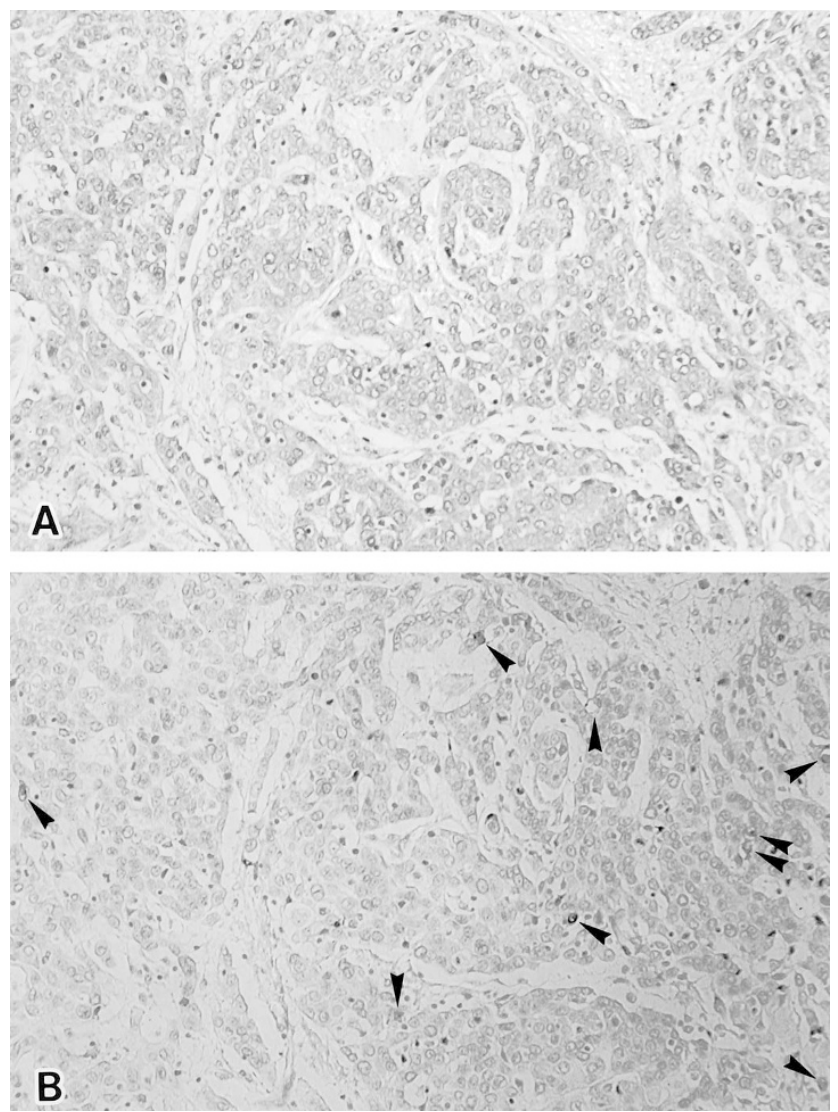

FIGURE 2. Cytoplasmic positivity with caspase-3 antibody (A) as well as scattered apoptotic cells (arrowheads) (B) were found, in an identical part of a case of esophageal SCC. (A) LSAB method; X 160, (B) TUNEL method; X 160 
(Fig. 1, A-B) were detected in an identical area, in which only a small number of TUNEL-positive lymphocytes were observed (Fig. 1B). The mean AI was $2.85 \%$ (range 0.60 to $7.40 \%$ ) in cases with caspase-3 immunoreactivity, and $1.66 \%$ (range 0.00 to $4.80 \%$ ) in cases without it. Cytoplasmic positivity with caspase-3 antibody (Fig. 2A) as well as scattered apoptotic cells (Fig. 2B) was found in an identical area. These findings accounted for the significant relationship between caspase-3 immunoreactivity and AI in esophageal SCCs $(P=.012)$.

We further studied the correlations among the expression of Bax or caspase-3, and AI in dysplasia adjacent to SCC. All dysplasia were determined according to standard criteria. We distinguished severe dysplasia from carcinoma in situ according to the existence of cytoplasmic maturation in the superficial layers. Forty-three of 50 (86.0\%) dysplasia were positive for Bax, and 23 of 48 (47.9\%) dysplasia were positive for caspase- 3 antibody. The mean AI was $1.18 \%$ (range 0.00 to $5.60 \%$ ). In a dysplasia, both Baximmunopositivity (Fig. 3A) and apoptotic cells (Fig. 3B) were detected in an identical area. The mean $\mathrm{AI}$ in cases with Bax immunoreactivity was $1.46 \%$ (range 0.00 to $5.60 \%$ ), and $0.23 \%$ (range 0.00 to $1.30 \%$ ) in cases without it. The mean AI in cases with caspase-3 immunoreactivity was $1.81 \%$ (range 0.00 to $5.60 \%$ ), and $0.66 \%$ (range 0.00 to $2.50 \%$ ) in cases without it. Figure 4 shows the relationship between Bax or caspase-3 immunoreactivity and AI in dysplastic and cancerous regions. Only in dysplasia, significant relationship was found between Bax expression and $\mathrm{AI}(P=$ .006) (Fig. 4A). Figure 4B shows the relationship between $\mathrm{AI}$ and caspase-3 immunoreactivities in dysplasia and cancerous regions, in both of which the significant relationships were found $(P=.016, P=.012)$.

We studied the correlation between AI and patients' prognosis. Patients were divided into two groups depending on whether the extent of cancer AI was above or below the median $(2.00 \%)$, according to previous reports $(25,26)$. The survival of patients with high AI tended to be higher than that of patients with low AI, but the difference was not significance $(P=.06)$.

In normal esophageal epithelium, rare apoptotic cells were seen in the surface epithelium, and AI could not been calculated.

Association between Bax, Caspase-3, p53, or Bcl-2 Protein Expression and Clinicopathologic Parameters including Patients' Prognosis

No significant relationship was found between Bax, caspase-3, p53, or Bcl-2 immunoreactivity and
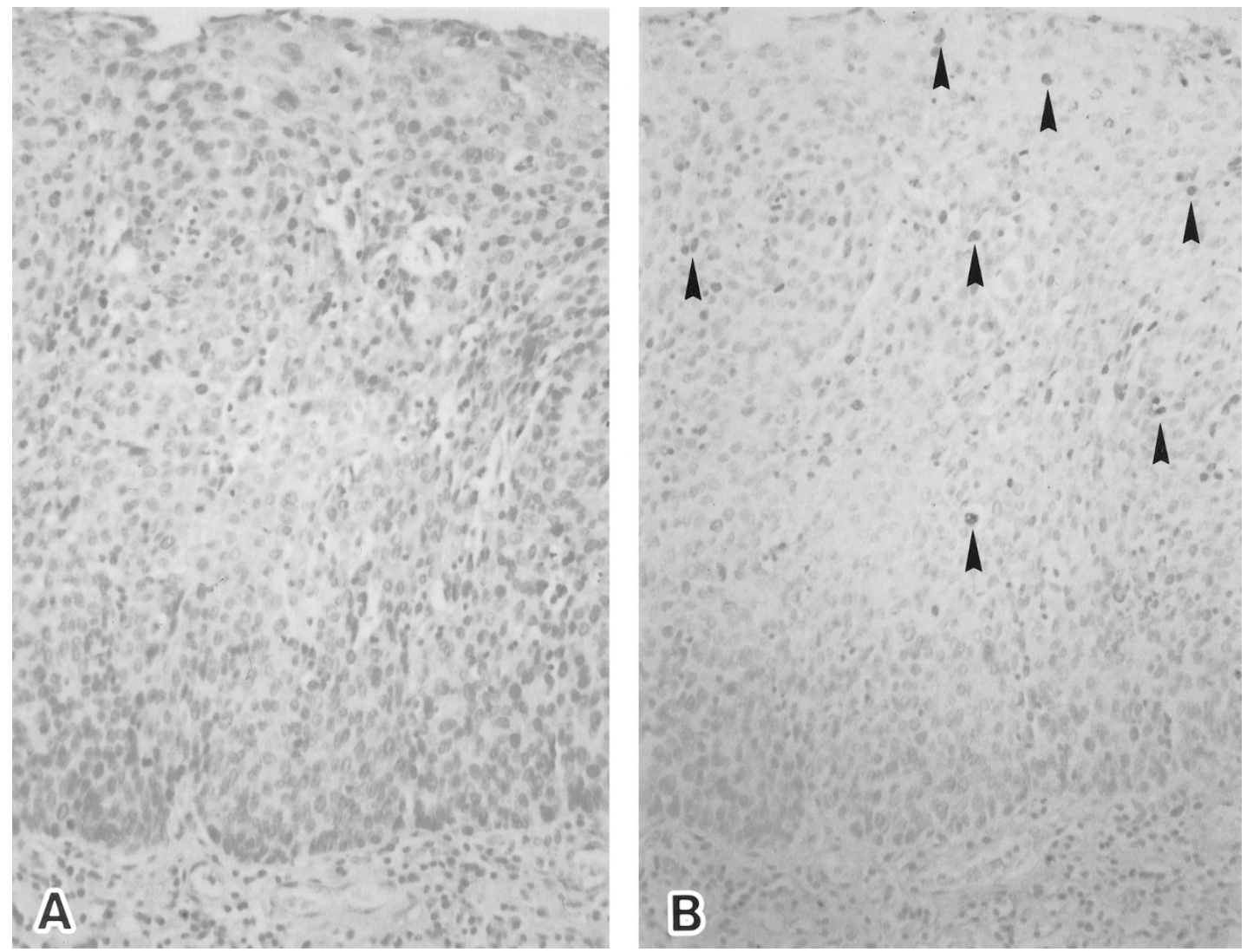

FIGURE 3. In a dysplasia, both Bax-immunopositivity (A) and apoptotic cells (arrowheads) (B) were detected in an identical part of a case of esophageal SCC. (A) ABC method; X 160, (B) TUNEL method; X 160 

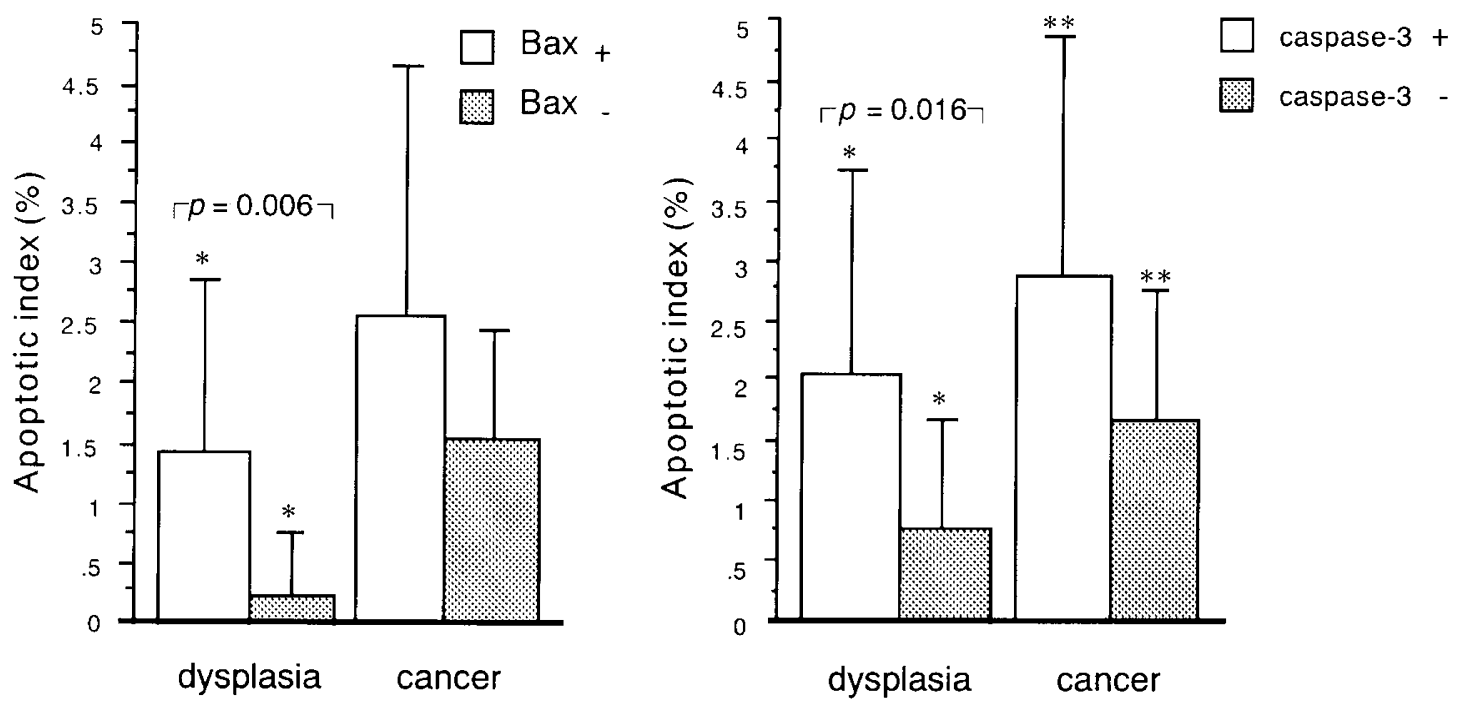

FIGURE 4. The association between Bax (A) or caspase-3 (B) immunoreactivity and apoptotic index. The significant relationship between expression of Bax and apoptotic index was found only in dysplasia $\left(\mathrm{a} ;{ }^{*} P<.006\right)$. On the other hand, the significant relationship between caspase-3 immunoreactivity and apoptosis index was found In both dysplasia and cancer. $\left(\mathbf{B} ;{ }^{*} P=.016,{ }^{* *} P=.012\right)$.

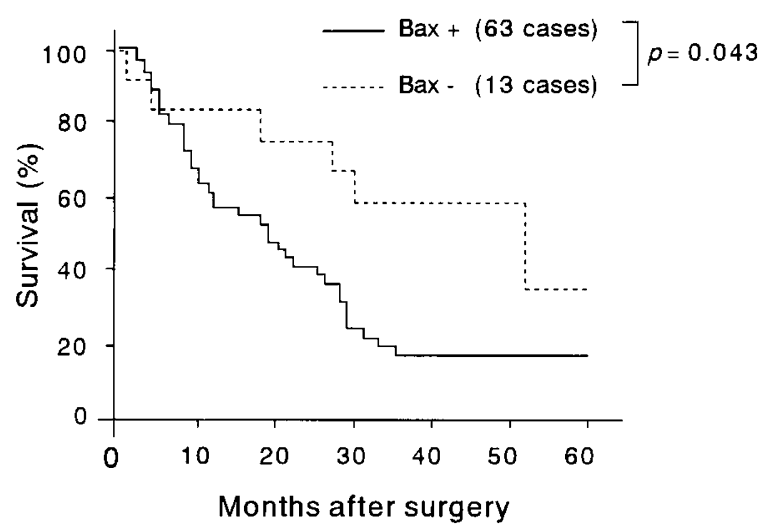

FIGURE 5. Cumulative Kaplan-Meier survival curves for patients with esophageal SCCs divided by the Bax immunopositivity. Bax-negative cases showed more favorable prognosis than Bax-positive cases.

various clinicopathologic parameters, including stage, histopathologic grade, lymphatic or vascular invasion, and patient age or sex. The survival of patients with Bax-positive tumors was significantly poorer than that of patients with Bax-negative tumors ( $P=.043$ ) (Fig. 5). There was no statistical difference in clinical stage between Bax-positive group and Bax-negative group (Table 3 ). On the other hand, there were no significant correlations between each caspase-3, Bcl-2, or p53 protein expression and patient prognosis $(P=.446, P=.934$, $P=.152$, respectively).

\section{DISCUSSION}

Bax protein has been established as a tumor suppressor, because Bax inactivation leads to rapid
TABLE 3. Bax Immunoreactivity and Clinical Stage in 76 Patients with Esophageal Squamous Cell Carcinoma

\begin{tabular}{|c|c|c|c|c|c|}
\hline \multicolumn{2}{|l|}{ Parameters $^{a}$} & \multirow{2}{*}{$\begin{array}{c}\text { Case } \\
\text { Number }\end{array}$} & \multicolumn{2}{|c|}{$\begin{array}{c}\text { Bax } \\
\text { Staining }\end{array}$} & \multirow{2}{*}{ p-Value } \\
\hline Group & Subset & & + & - & \\
\hline \multirow[t]{5}{*}{ Stage } & $\mathrm{O}$ & 9 & 6 & 3 & 0.16 \\
\hline & I & 16 & 11 & 5 & \\
\hline & II & 19 & 17 & 2 & \\
\hline & III & 24 & 21 & 3 & \\
\hline & Iva & 8 & 8 & 0 & \\
\hline \multirow[t]{6}{*}{ Depth of invasion } & Tis & 2 & 1 & 1 & 0.16 \\
\hline & Tla & 5 & 3 & 2 & \\
\hline & $\mathrm{T} 1 \mathrm{~b}$ & 22 & 16 & 6 & \\
\hline & $\mathrm{T} 2$ & 13 & 12 & 1 & \\
\hline & T3 & 26 & 23 & 3 & \\
\hline & $\mathrm{T} 4$ & 8 & 8 & 0 & \\
\hline \multirow[t]{5}{*}{ Lymph node metastasis } & n0 & 41 & 31 & 10 & 0.21 \\
\hline & n1 & 7 & 7 & 0 & \\
\hline & $\mathrm{n} 2$ & 19 & 18 & 1 & \\
\hline & n3 & 7 & 5 & 2 & \\
\hline & $\mathrm{n} 4$ & 2 & 2 & 0 & \\
\hline
\end{tabular}

${ }^{a}$ All parameters listed were referred from the Guidelines for Clinical and Pathological Studies on Carcinoma of the Esophagus (Japanese Society for Esophageal Disease, 1999). All cases had no distant metastasis.

tumor growth and to a decrease in the extent of spontaneous apoptosis of tumor cells (27). Krajewski et al. reported that loss of Bax immunopositivity was strongly associated with tumor progression and shorter survival of patients with metastatic breast adenocarcinoma (20). On the other hand, there have been a number of recent studies finding no significant difference between Bax protein immunoreactivity and $\mathrm{AI}$ in either oral and oropharyngeal cancers or bronchial SCCs $(16,21)$.

Somatic frameshift mutation of the Bax gene eliminating production of Bax protein has been 
demonstrated in colon, gastric and endometrial cancers, and hematopoietic malignancies (28-30). A good correlation between the presence of such mutation and lack of immunostaining by antibody to Bax protein was also demonstrated in endometrial carcinomas (28). In the present study, Bax immunopositivity independent of Bcl-2, caspase-3, and p53 immunoreactivities was significantly associated with poor prognosis inpatients with esophageal SCCs. Furthermore, no significant relationships were observed between Bax expression and AI in esophageal SCCs. These findings suggested that the functional abnormality of immunopositive Bax protein detected in esophageal SCCs cannot be explained by this Bax gene frameshift mutation.

To identify potential intermediate biomarkers in the multistep processes of human esophageal SCC progression, we also tested for Bax and caspase-3 expression and AI in dysplasia adjacent to SCC. Several reports have described extent of AI in preneoplastic lesions in various types of tissue. However, studies on the relationship between Bax immunoreactivity and AI in preneoplastic lesions are rare $(21,23)$. In bronchial dysplasia, no correlation was found between expression of Bax protein and apoptotic activity (21). Interestingly, in the present study, in dysplasia, the AI in Bax-positive lesions was significantly higher than that in Bax-negative lesions, whereas there was no significant correlation between Bax expression and AI in cancerous regions. Our in vivo findings for esophageal SCCs suggest that Bax protein expressed in cancerous regions may lose its death-promoting activity. On the other hand, immunopositivity of caspase- 3 retaining its death-promoting activity was found in both dysplasia and cancerous regions, whereas no significant relationship was found between caspase-3 immunoreactivity and any clinicopathologic parameter, including patients' prognosis. These findings suggest that although caspase- 3 retains its death-promoting activity, the rate of tumor cell proliferation may be higher than that of apoptosis in esophageal SCCs. Other than the Bax protein cascade of apoptosis, transmembrane proteins of Fas and Fas ligand (FasL) are known as deathpromoting factors associated with the activation of caspase-3. Binding of FasL to Fas induced trimerization of the Fas receptor, which recruits caspase-8 via an adaptor, FADD/MORT1, to activate caspase-3 protein. A previous study reported that about $30 \%$ of human esophageal SCCs expressed Fas protein (31). Therefore, most likely not p53-Bax but the Fas-FasL cascade predominantly activates caspase-3 protein in cancerous regions of esophageal SCCs.

In this study, all patients underwent mild chemotherapy preoperatively. Previous study by Moreira et al. demonstrated that in esophageal SCC, preop- erative radiation therapy or radio-chemotherapy increased number of apoptotic cells, but only chemotherapy group did not show a significantly increased number of apoptotic cells against nontreated control group (32). They performed continuous infusion of 5 -fluorouracil $\left(300 \mathrm{mg} / \mathrm{m}^{2}\right)$ administered on Days 1 to 5, combined with a single infusion of cis-dichlorodiamino-cisplatin (50 $\left.\mathrm{mg} / \mathrm{m}^{2}\right)$ and bleomycin $\left(30 \mathrm{mg} / \mathrm{m}^{2}\right)$ on Day 1 . However, in the present study, all patients had received chemotherapy with only bleomycin $\left(20 \mathrm{mg} / \mathrm{m}^{2}\right)$ daily orally administered over 5 days. Our chemotherapy was milder than that of previous study, therefore we think that preoperative mild chemotherapy alone had little effect on the differences in AI.

Our data demonstrated that the survival of patients with Bax-positive tumors was significantly poorer than that of patients with Bax-negative tumors $(P=.043)$. However, this $p$-value was almost borderline as a significant difference $(P<.05)$. Further investigation of Bax protein expression in tumor progression will be required to confirm the present finding of esophageal SCC.

In conclusion, our findings support the hypothesis that Bax protein expressed in cancerous regions but not dysplasia loses death-promoting apoptotic activity, and cannot contribute to suppression of the tumor progression leading to poor prognosis in some cases of human esophageal SCC. Further investigation of Bax at the DNA and/or RNA level will be required to confirm the present findings.

Acknowledgments: The authors are grateful to Dr. T. Moriki for providing clinical materials.

\section{REFERENCES}

1. Miyashita T, Krajewski S, Krajewska M, Wang HG, Lin HK, Liebermann DA, et al. Tumor suppressor p53 is a regulator of bcl-2 and Bax gene expression in vitro and in vivo. Oncogene 1994;9:1799-805.

2. Oltvai ZN, Milliman CL, Korsmeyer SJ. Bcl-2 heterodimerization in vivo with a conserved homology, Bax, that accelerates programmed cell death. Cell 1993;74:609-19.

3. Kroemer G. The proto-oncogene bcl-2 and its role in regulating apoptosis. Nature Med 1997;3:614-20.

4. Huang DCS, O'Reilly LA, Strasser A, Cory S. The antiapoptosis function of bcl-2 can be genetically separated from its inhibitory effect on cell cycle entry. EMBO J 1997; 16:4628-38.

5. White E. Life death, and the pursuit of apoptosis. A review. Gene Dev 1996;19:1-15.

6. Yang E, Korsmeyer SK. Molecular thanatopsis 58 A discourse on the bcl-2 family and cell death. Blood 1996;88:386-401.

7. Yang J, Liu X, Bhalla K. Prevention of apoptosis by bcl-2 58 release of cytochrome c from mitochondria blocked. Science 1997;275:1129-32.

8. Liu X, Naekyung C, Yang J, Jemmerson R, Wang J. Induction of apoptotic program in cell-free extracts 58 requirement for dATP and cytochrome c. Cell 1996;86:147-57. 
9. Kluck RM, Bossy-Wetzel E, Green DR, Nwemeyer DD. The release of cytochrome $\mathrm{c}$ from mitochondria 58 a primary site for bcl-2 regulation of apoptosis. Science 1997;275:1132-6.

10. Manon S, Chaudhuri B, Guerin M. Release of cytochrome c and decrease of cytochrome c oxidase in bax-expressing yeast cells, and prevention of these effects by coexpression of bcl-xL. FEBS Lett 1997;415:29-32.

11. Li P, Nijhawan D, Budihardjo I, Srinivasula SM, Ahmad M, Alnemri ES, et al. Cytochrome c and dATP-dependent formation of Apaf-1/caspase-9 complex initiates an apoptotic protease cascade. Cell 1997;91:479-89.

12. Enari M, Sakahira H, Yokoyama H, Okawa K, Iwamatsu A, Nagata S. A caspase-activated DNase that degrades DNA during apoptosis, and its inhibitor ICAD. Nature 1998;391: 43-50.

13. Janicke RU, Sprengart ML, Wati MR, Porter AG. Caspase-3 is required for DNA fragmentation and morphological changes associated with apoptosis. J Biol Chem 1998;273:9357-60.

14. Sarbia M, Bittinger F, Grabellus F, Verreet P, Dutkowski P, Willers R, et al. Expression of Bax, a proapoptotic member of the Bcl-2 family, in esophageal squamous cell carcinoma. Int J Cancer 1997;73:508-13.

15. Jordan RCK, Catzavelos GC, Barrett AW, Speight PM. Differential expression of bcl-2 and bax in squamous cell carcinomas of the oral cavity. Oral Oncol Eur J Cancer 1996;32B: $394-400$.

16. Ito T, Fujieda S, Tuzuki H, Sunaga H, Fan G, Sugimoto C, et $a l$. Decreased expression of Bax is correlated with poor prognosis in oral and oropharyngeal carcinoma. Cancer Lett 1999;140:81-91.

17. Krajewski S, Thor AD, Edgerton SM, Moore DH II, Krajewska M, Reed JC. Analysis of Bax and Bcl-2 expression in p53immunopositive breast cancers. Clin Cancer Res 1997;3:199-208.

18. Sturm I, Kohne CH, Wolff G, Petrowsky H, Hillebrand T, Hauptmann S, et al. Analysis of the p53/BAX pathway in colorectal cancer: low BAX is a negative prognostic factor in patients with resected liver metastases. J Clin Oncol 1999;17: 1364-74.

19. Bukholm IK, Nesland JM. Protein expression of p53, p21 (WAF1/CIP1), bcl-2, Bax, cyclin D1 and pRb in human colon carcinomas. Virchows Arch 2000;436:224-8.

20. Krajewski S, Blomqvist C, Franssila K, Krajewska M, Wasenius VM, Niskanen E, et al. Reduced expression of proapoptotic gene BAX is associated with poor response rates to combination chemotherapy and shorter survival in women with metastatic breast adenocarcinoma. Cancer Res 1995;55: 4471-8.
21. Törmänen U, Nuorva K, Soini Y, Pääkkš P. Apoptotic activity is increased in parallel with the metaplasia-dysplasiacarcinoma sequence of the bronchial epithelium. Br J Cancer 1999;79:996-1002.

22. Ishikawa T, Furihata M, Ohtsuki Y, Ono H, Inoue A, Ogoshi S. Aberrant expression of p53 and retinoblastoma gene products in human esophageal squamous cell carcinoma. Int J Oncol 1997;11:1109-14.

23. Izawa H, Yonemitsu N, Shin T, Sugihara H. Histopathological analysis of apoptosis, and expression of p53, bcl-2, bax, and Ki-67 in laryngeal squamous cell carcinomas and dysplasia. Auris Nasus Larynx 1999;26:317-30.

24. Matsuura T, Kuratate I, Teramachi K, Osaki M, Fukuda Y, Ito $\mathrm{H}$. Thymidine phosphorylase expression is associated with both increase of intratumoral microvessels and decrease of apoptosis in human colorectal carcinomas. Cancer Res 1999; 59:5037-40.

25. Paxton JR, Bolger BS, Armour A, Symonds RP, Mao JH, Burnett RA. Apoptosis in cervical squamous carcinoma: predictive value for survival following radiotherapy. J Clin Pathol 2000;53:197-200.

26. Ikeguchi M, Cai J, Yamane N, Maeta M, Kaibara N. Clinical significance of spontaneous apoptosis in advanced gastric adenocarcinoma. Cancer 1999;85:2329-35.

27. Yin C, Knudson CM, Korsmeyer SJ, Dyke TV. Bax suppresses tumorigenesis and stimulates apoptosis in vivo. Nature 1997;385:637-40.

28. Catasus L, Guiu MX, Machin P, Munoz J, Prat J. Bax somatic frameshift mutations in endometrioid adenocarcinomas of the endometrium: evidence for a tumor progression role in endometrial carcinoma with microsatellite instability. Lab Invest 1998;78:1439-44.

29. Yamamoto H, Sawai H, Perucho M. Frameshift somatic mutations in gastrointestinal cancer of the microsatellite mutator phenotype. Cancer Res 1997;57:4420-6.

30. Meijerink JPP, Mensink EJBM, Wang K, Sedlak TW, Sloetjes AW, Witte TD, et al. Hematopoietic malignancies demonstrate loss-of-function mutation of Bax. Blood 1998;91:2991-7.

31. Shibakita M, Tachibana M, Dhar DK, Kotoh T, Kinugasa S, Kubota H, et al. Prognostic significance of Fas and Fas ligand expressions in human esophageal cancer. Clin Cancer Res 1999;5:2464-9.

32. Moreira LF, Naomoto Y, Hamada M, Kamikawa Y, Orita K. Assessment of apoptosis in oesophageal carcinoma preoperatively treated by chemotherapy and radiotherapy. Anticancer Res 1995;15:639-44. 